\title{
Review on Assessment of Self-Medication and Factors Influencing Self-Medication Practice among Pediatric Population
}

\author{
AR Shabaraya ${ }^{1}$, Akhila Ullas ${ }^{2}$ \\ ${ }^{1}$ Professor \& Head, Department of Pharmacy Practice, ${ }^{2}$ Student Pharm D, Department of Pharmacy Practice, \\ Srinivas College of Pharmacy, Valachil, Mangalore, Karnataka-574143
}

Corresponding Author: Akhila Ullas

\begin{abstract}
Self-medication refers to patients who use nonprescription medicines, usually over-the-counter (OTC) drugs, to treat certain 'minor' ailments themselves without consulting a medical practitioner and without any medical supervision. In pediatric context, selfmedication implies administration of medication by the care giver without medical consultation. Parents sometimes exhibit the habit of selfmedication for the diseases of their children. Today, children take responsibility for their medications at different ages; children often take responsibility for taking medications at a young age especially when they are suffering from chronic conditions. Children aged 16-18 years are observed to self-medicate for minor ailments like cold, fever, headache and pain. Hence this population is at a greater risk of medication errors and there is a need to improve the pediatric medication safety. Various factors influencing self-medication are patient and care giver educational level, awareness about health, accessibility to medicine and health care facilities, time constraint, ineffective prescription, thinking disease is not serious, ease and convenience, cost of physician's service development of new technologies (e.g. internet and related communication) is promoting selfmedication worldwide. Economic and cultural factors have contributed to the growth and spread of self-medication worldwide. The remaining of the previous prescription drugs which are present at home is used, previous experience on efficacy of the drug. This systematic review of self-medication in pediatric
\end{abstract}

population studies showed that more than half of the populations were self-medicated.

Keywords: self-medication, pediatric population

\section{INTRODUCTION}

Self-medication refers to patients who use non-prescription medicines, usually over-the-counter (OTC) drugs, to treat certain 'minor' ailments themselves without consulting a medical practitioner and without any medical supervision. In pediatric context, self-medication implies administration of medication by the care giver without medical consultation ${ }^{1}$. Parents sometimes exhibit the habit of selfmedication for the diseases of their children $^{2,3}$. The success of providing rational drug use for children is depend on the attitude of the parents. The pediatric population ranges from the age of $0-18$ years, i.e.; from infancy to adolescence. Today, children take responsibility for their medications at different ages; children often take responsibility for taking medications at a young age especially when they are suffering from chronic conditions ${ }^{5}$. Children aged 16-18 years are observed to selfmedicate for minor ailments like cold, fever, headache and pain. Hence this population is at a greater risk of medication errors and there is a need to improve the pediatric medication safety.

Various factors influencing selfmedication are 
- patient and care giver educational level

- awareness about health

- accessibility to medicine and health care facilities

- time constraint

- ineffective prescription

- thinking disease is not serious

- ease and convenience

- cost of physician's service

- Development of new technologies (e.g. internet and related communication) is promoting self-medication worldwide.

- Economic and cultural factors have contributed to the growth and spread of self-medication worldwide.

- The remaining of the previous prescription drugs which are present at home is used

- previous experience on efficacy of the $\operatorname{drug}^{6,7,8}$

The public may prefer the medical store as their source for medicine as the waiting time may be less, medical stores present nearer to their place of residence and the process is less expensive as the public can avoid paying consultation fee and other charges.

Younger children are often given medications by their parents, whereas older adolescents may self-medicate ${ }^{9}$. Pediatric OTC drugs cover a wide range of medications including cough, cold medicines (CCMs), antipyretic analgesics (e.g. paracetamol and ibuprofen), vitamin supplements and dermatological products, etc. This will account for the vast majority of all pediatric OTC drugs ${ }^{11}$. Most of the pediatric OTC drugs, such as vitamin supplements and dermatological preparations, are safe when used properly, i.e. according to the package insert. Nevertheless, parents and adolescents may have insufficient knowledge about the medicines they use, which can lead to inappropriate drug use - even to serious, adverse drug effects among self-medicating children and adolescents ${ }^{8,12}$.

Self-medication has both benefits and risks. Responsible self-medication can save scarce medical resources from being wasted on minor conditions, reduce the burden on health care facilities, and decrease the cost and time people spend to visit health care facilities for minor symptoms. Most of them used previous prescription to procure the drugs and previous experience on efficacy ${ }^{13}$. However, inappropriate self-medication can have a number of potential risks for example delay in seeking appropriate medical advice; failure to recognize or self-diagnose contraindications, interactions with prescribed medicinal products; failure to report current self-medications to the prescribing physician (risk of double medication and/or harmful interaction); inappropriate duration of use of medicine; risk of dependence and abuse etc ${ }^{6}$.

Self-management has been defined as an "individual's ability to manage the symptoms, treatment, physical and psychosocial consequences and lifestyle changes inherent in living with a chronic

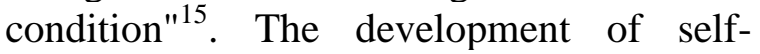
management skills is a critical part of the transition to adulthood for adolescents with a diagnosis of lifelong chronic illness, and failure to develop these skills can prevent successful transition to adult care. Difficulties with self-management in late adolescence and young adulthood may be exacerbated by the transition to new providers and changes in insurance ${ }^{16}$. In most of the United States, public health plans such as Medicaid, SCHIP and the federal Title V program facilitate access to comprehensive health care for $\mathrm{CSHCN}$ through age 18, at which point patients typically "age out" of coverage. The problem of poor outcomes in the transition period has been demonstrated in multiple populations $^{21}$.

The main problem with selfmedication with antibiotics is the emergence of resistance. A clear relationship exists between microbial resistance and amount of antibiotic use $\mathrm{e}^{23}$. Other causes of antibiotic resistance are antibiotic overuse, clinician's over-prescription, a strong belief by the 
public in antibiotics such as hoarding and non-prescription purchase ${ }^{19}$. Other human malpractices that have contributed to the emergence and spread of antibiotic resistance include inappropriate antibiotic use, inadequate dosing and incomplete doses $^{8}$.

Very few pediatrics OTC drugs have been adequately tested for safety and efficacy among child populations; the dosages of most pediatric OTC drugs have been extrapolated from adult clinical and pharmacological data ${ }^{17}$.

\section{RESULT \& DISCUSSION}

Self-medication is an uprising dilemma in the society among pediatric population especially due to their easy availability and flexibility in the system. Francis S V T Pereira et al., conducted a study on self-medication in children and adolescents and found that more than half of the population were self-medicated ${ }^{1}$. Aster Desalew Kassie et al., conducted a study in Meket District, Northeast Ethiopia on Selfmedication practice and associated factors among adult household members. According to the study it has been found that the important problems associated with self-medication practice have been identified that drug resistance, drug side effects, wastage of resources, and serious health hazards including death. Most of the study participants practiced self-medication. The study concluded that the reasons for self-medication are previous experience of self-medication, accessibility of pharmacies and presence of medication at home. So, strengthening the communities' awareness on drug side effects and integrated efforts of individuals, communities, health facilities, and regulatory bodies are highly necessary ${ }^{2}$.

Abdul-Mohsin Jassim conducted a study on prevalence of self-medication with antimicrobial drugs. The study was conducted in 300 households to determine the prevalence of self- medication with antimicrobials. The subjects were also asked whether they are exchanged the drugs among the family members and their relatives, friends or neighbors, and if they normally completed the prescribed dose. A majority of the families (78\%) admitted to practicing self-medication. Pereira FS et al., conducted a study on Self-medication in children and adolescents, to evaluate the prevalence of self-medication in children and adolescents and to compare the results with sociodemographic indicators and with the help of health care services. The prevalence of self-medication was $56.6 \%$. The Mothers and drugstore employees are more frequently responsible for the selfmedication. The commonly using selfmedication were respiratory diseases (17.2\%), fever (15\%), and headache (14\%). Subjects were in the group of 7-18 years and public health care users showed that there is an increased risk for the self-medication ${ }^{3}$.

Sridevi A Naaraayan et al, conducted a study on prevalence of selfmedication among children was found to be $32 \%$ which is similar to the $37 \%$ prevalence in urban area observed in the study conducted by NIN, Hyderabad, India. These results are also similar to a $25 \%$ prevalence of self-medication observed in German study, the largest one with a sample size of 17,450 children. Some studies are showing prevalence as high as $50-70 \%$. Previous studies have shown that self-medication is more common with the educated and affluent. The fact that their study population mainly belonged to lower socio economic class, could be responsible for lower rate of self-medication in their subjects. Further, self-medication may be considered as an indirect indicator of quality of health care services and hence prevalence of selfmedication is low in their region due to better access to health care. Fever, cough and cold were the most common symptoms that were treated by self-medication in this study which is similar to many studies. Usage of antibiotics as self-medication is strictly condemnable as it leads to emergence of antibiotic resistance. Though some anticold medications are approved for sale over-the-counter, their use in young children has resulted in many complications 
including death and hence they are approved by FDA for use in children more than 2 years only. Not many studies bring out whether patients resort to polypharmacy. Average duration of 2.5 days observed in their study is similar to that observed in other studies. Previous prescription was most commonly used to procure the drug. Other common sources were pharmacist and mother. This is against other studies which state pharmacist or mother as the commonest source. Possible reasons could be the low educational level of mothers as represented by lower socio economic class. Further using previous prescription gives parents a false sense of security that the treatment is medically correct. On the contrary, lack of clinical assessment by qualified medical professional results in overlooked diagnosis and inappropriate treatment. The observation that children of older age were more commonly selfmedicated than younger children, is supported by other studies. Other demographic factors like sex, area of residence-urban and rural, distance from nearest health facility and socioeconomic class did not have a statistically significant association with self-medication. This may reflect the perspective that the factor underlying self-medication is the attitude rather than necessity ${ }^{6}$.

According to Erica F Lawson et al, self-management has been defined as an "individual's ability to manage the symptoms, treatment, physical and psychosocial consequences and lifestyle changes inherent in living with a chronic condition". The development of selfmanagement skills is a critical part of the transition to adulthood for adolescents with a diagnosis of lifelong chronic illness, and failure to develop these skills can prevent successful transition to adult care. Difficulties with self-management in late adolescence and young adulthood may be exacerbated by the transition to new providers and changes in insurance. In most of the United States, public health plans such as Medicaid, SCHIP and the federal
Title $\mathrm{V}$ program facilitate access to comprehensive health care for CSHCN through age 18, at which point patients typically "age out" of coverage. The problem of poor outcomes in the transition period has been demonstrated in multiple populations $^{12}$.

\section{CONCLUSION}

Many of the studies showed that self-medication in pediatric population more than half of the population were selfmedicated. It was seen that people using drugs usually for self-medication are OTC medications especially for fever, cold, headache, vomiting, diarrhea and cough. There are many reason found that for selfmedication includes knowledge about the drugs, whether they had the same symptoms previously, not getting time to go to physicians, worried about the cost of the treatment. This may reflect the perspective that the factor underlying self-medication is the attitude rather than necessity. Selfmedication is more common in older children than younger children. The pediatric population, being a special population is in need of more vigilance and care to avoid self-medication errors and toxicity.

\section{Acknowledgement: None}

Conflict of Interest: None

\section{Source of Funding: None}

\section{REFERENCES}

1. Francis S. V. T. Pereira, Fabio Bucaretchi, Celso Stephan, Ricardo Cordeiro Selfmedication in children and adolescents' Pediatr, 2007; 83(5):453-8.

2. Aster Desalew Kassie, Berhanu Boru Bifftu and Habtamu Sewunet Mekonnen *Selfmedication practice and associated factors among adult household members in Meket district, Northeast Ethiopia, 2018, volume 19,8 .

3. Pereira FS, Bucaretchi F, Stephan C, Cordeiro R. Self-medication in Children and 
Adolescents [automedicação Em Crianças E Adolescentes]. Journal de pediatria, 2007.

4. Gohar UF, Khubaib S, Mehmood A. Selfmedication trends in children by their parents. J Develop Drugs, 2017; 6(2):1-7.

5. Jassim A. In-home Drug Storage and Selfmedication with Antimicrobial Drugs in Basrah, Iraq, Oman Medical Journal. 2010; 25 (2): 79-87.

6. Sridevi A Naaraayan, I. Rathinabalan, V. Seetha. Self-medication pattern among children attending a tertiary hospital in South India: a cross-sectional study, International Journal of Contemporary Pediatrics, 2016 Nov; 3(4):1267-1271.

7. Janne Fangel Jensen, Mathilde Gottschau, Volkert Dirk Siersma, Anette Hauskov Graungaard et al, Association of Maternal SelfMedication and Over-the-Counter Analgesics for Children, American academy of paediatrics, $1 \mathrm{Feb}$ 2014, Vol. 133, Issue 2.

8. Mabrook Mohanna, Self-medication with Antibiotic in Children in Sana'a City, Yemen, Oman Med J. 2010 Jan; 25(1): 4143.

9. Pius G. Horumpende, Sophia H. Said, Jaffu O. Chilongola, Festo S. Mazuguni, Magreth L. Antony, Tolbert B. Sonda et al, Prevalence, determinants and knowledge of antibacterial self-medication: A cross sectional study in North-eastern Tanzania, PLoS One. 2018; 13(10).

10. Mariam TG. Assessment of knowledge and practice on appropriate use of drugs in urban and rural communities in Jimma Zone, South West Ethiopia. Ethiop J Health Sci, 1998; 8(2): 89-97.

11. McD Taylor D, Robinson J, MacLeod D, MacBean CE, Braitberg G. Therapeutic errors among children in the community setting: Nature, causes and outcomes. J Paediatr Child Health 2009; 45:304-9.

12. Erica F Lawson, Aimee O Hersh, Mark A Applebaum, Edward H Yelin, Megumi J Okumura, and Emily von Scheven, Selfmanagement skills in adolescents with chronic rheumatic disease: A cross-sectional survey, Pediatr Rheumatol Online J. 2011; 9: 35 .

13. Abinash Panda, Supriya Pradhan, Gurukrushna Mohapatra, Jigyansa Mohapatra, Drug-related problems associated with self-medication and medication guided by prescription: A pharmacy-based survey, Indian $\mathbf{J}$ Pharmacol, 2016 Sep-Oct; 48 (5): 515-521.

14. Grace-Ange Elong Ekambi, Cécile Okalla Ebongue, Ida Calixte Penda, Emmanuel Nnanga Nga, Emmanuel Mpondo Mpondo, Carole Else Eboumbou Moukoko, Knowledge, practices and attitudes on antibiotics use in Cameroon: Selfmedication and prescription survey among children, adolescents and adults in private pharmacies, PLoS One. 2019, Published online 2019 Feb 28.

15. Calixte Ida Penda, Else Carole Eboumbou Moukoko, Julien Franck Ngomba Youmba, Emmanuel Mpondo Mpondo, Characterization of pharmaceutical medication without a medical prescription in children before hospitalization, Pan Afr, Med J. 2018; 30: 302. Published online 2018 Aug 31.

16. Turki Homod Albatti, Shahd Alawwad, Roqaih Aldueb, Razan Alhoqail, Rawan Almutairi, The self-medication use among adolescents aged between 13-18 years old; Prevalence and behaviorInt J Pediatr Adolesc Med. 2017 Mar; 4(1): 19-25.

17. Andréa Dâmaso Bertoldi, Marysabel Pinto Telis Silveira, Ana M.B. Menezes, Maria Cecília Formoso Assunção, Helen Gonçalves, Pedro Curi Hallal, Tracking of Medicine Use and Self-Medication from Infancy to Adolescence, J Adolesc Health. 2012 Dec; 51(6): S11-S15.

18. Shabnam Nazir, Marium Azim, Assessment of antibiotic self-medication practice among public in the northwestern region of Pakistan, Eur J Hosp Pharm. 2017 Jul; 24(4): 200-203.

19. Mariane Corrêa-Fissmer, Mariana Gaspar Mendonça, Anesio Henrique Martins, Dayani Galato, Prevalence of selfmedication for skin diseases: a systematic review, An Bras Dermatol. 2014 JulAug; 89(4): 626-630.

20. Petruța Tarciuc, Ana Maria Alexandra Stanescu, Camelia Cristina Diaconu, Luminita Paduraru, Alina Duduciuc, Smaranda Diaconescu, Patterns and Factors Associated with Self-Medication Among the Pediatric Population, Medicina (Kaunas) 2020 Jun; 56(6): 312.

21. Sirak Tesfamariam, Indermeet Singh Anand, Ghide Kaleab, Samson Berhane, Biruck Woldai, Eyasu Habte, Mulugeta Russom, Self-medication with over the 
counter drugs, prevalence of risky practice and its associated factors in pharmacy outlets,BMC Public Health. 2019; 19: 159.

22. Kazeem A Oshikoya, Idowu O Senbanjo, Olisamedua F Njokanma, Self-medication for infants with colic in Lagos, Nigeria,BMC Pediatr. 2009; 9: 9.

23. Pavani Rangachari, Kathleen R. May, Lara M. Stepleman, Martha S. Tingen, Stephen Looney et al, nt J Environ Res Public Health. 2019 Sep; 16(17): 3060.

24. iayao Xu, Xiaomin Wang, Kai Sing Sun, Leesa Lin, Xudong Zhou, Parental selfmedication with antibiotics for children promotes antibiotic over-prescribing in clinical settings in China, Antimicrob Resist Infect Control. 2020; 9: 150.

25. F C Jemaa, A Khaldi, L Bessioud, J Borhene, TAkkad, G Ltaief, 1304 Self Medication in Children at the District of Tunis (Tunisia): Focus on Antibiotic Self Medication, Pediatric Research volume 68, page 645, (2010).
26. Shabaraya A R, Rajendra S D., Vishnu Sharma M., Suresh B., Effect of inhaled formoterol and budesonide combination and effect of patient education in asthma- Indian Journal of Hospital Pharmacy Jan- Feb 2008

27. Shabaraya A R, Rajendra S D., Suresh B., 'Patient's Views' A key to assess burden of Asthma-Indian Journal of Hospital Pharmacy, Vol. 46(2), March-April-2009. ISSN 0019-526X. Pg. No. 19.

28. Keerthana Ramesh, Anasuya P., A. R. Shabaraya "A Review on Medication Adherence in Hypertensive Patients" World Journal of Pharmacy and Pharmaceutical Sciences Volume 9, Issue 7, 2020, 744-753 ISSN 2278-4357.

How to cite this article: AR Shabaraya, Ullas A. Review on assessment of self-medication and factors influencing self-medication practice among pediatric population. International Journal of Research and Review. 2021; 8(4): 47-52. DOI: https://doi.org/10.52403/ijrr. 20210408 